\title{
A Criação de Amigos Imaginários: Uma Revisão de Literatura
}

\author{
Natália Benincasa Velludo \\ Débora de Hollanda Souza \\ Universidade Federal de São Carlos \\ São Carlos, SP, Brasil
}

\begin{abstract}
RESUMO
A brincadeira de faz de conta representa um importante marco no desenvolvimento infantil. Entre as diversas formas que a brincadeira simbólica pode assumir, uma se destaca por suas características singulares: a criação de amigos imaginários. Embora o fenômeno já tenha sido associado a diferentes aspectos positivos do desenvolvimento, as pesquisas nacionais sobre o tema são escassas. O presente trabalho pretende contribuir para esse campo de estudos, apresentando uma revisão sistemática da literatura sobre amigos imaginários. A pesquisa bibliográfica foi feita por meio de uma análise de livros e artigos indexados nas bases de dados SciELO-Brasil, Index Psi, PePSIC, LILACS e PsycINFO. No total, foram encontrados 46 trabalhos nacionais e estrangeiros, publicados entre 1934 e 2013. A literatura sugere que a criação de amigos imaginários é associada a ganhos importantes, por exemplo, em criatividade, sociabilidade e cognição social. Sugerem-se, portanto, direções futuras para o desenvolvimento desta linha de pesquisa no país.
\end{abstract}

Palavras-chave: Amigo imaginário; Brincar de faz de conta; Crianças.

\section{ABSTRACT}

\section{The Creation of Imaginary Companions: A Literature Review}

Pretend play is an important milestone in child development. Among the many forms that symbolic play can take, one stands out for its singularity: the creation of imaginary companions. The phenomenon has been associated with various positive aspects of development, however, there are very few Brazilian studies investigating this topic. The present research aims to contribute to this study field by presenting a systematic literature review on imaginary companions. The literature review was based on the analysis of indexed books and articles found in SciELO-Brasil, Index Psi, PePSIC, LILACS and PsycINFO databases, published between 1934 and 2013. In total, 46 national and foreign papers, published between 1934 and 2013, were found. The literature suggests that the creation of imaginary companions is associated with important gains, for example, in creativity, sociability and social cognition. Therefore, future directions for this line of research in the country are suggested.

Keywords: Imaginary companion; Pretend play; Children.

\section{RESUMEN}

\section{La Creación de Amigos Imaginarios: Una Revisión de la Literatura}

El juego de hacer de cuenta es un aspecto importante en el desarrollo infantil. De entre las varias formas que el juego simbólico puede tomar, una se destaca por sus singularidades: la creación de amigos imaginarios. El fenómeno ha sido asociado con varios aspectos positivos del desarrollo, sin embargo, hay pocos estudios brasileros en este tema. Esta investigación se propone contribuir a este campo de estudio presentando una revisión sistemática de la literatura en amigos imaginarios. La búsqueda bibliográfica se basó en el análisis de libros y artículos indexados en las bases SCIELO-Brasil, Index Psi, PePSIC, LILACS y PsycINFO publicados entre 1934 y 2013. En total, se encontraron 46 estudios nacionales e extranjeros, publicados entre 1934 y 2013. La literatura sugiere que la creación de amigos imaginarios se asocia con importantes ganancias en el desarrollo, como la creatividad, la sociabilidad y la cognición social. Por tanto, se sugieren futuras líneas de investigación en esta área en nuestro país.

Palabras clave: Amigo Imaginario; Hacer de cuenta; Niños. 
A brincadeira de faz de conta representa um importante marco no desenvolvimento humano (Leslie, 1987). Ela surge, em geral, entre os 18 e 24 meses de vida (Piaget \& Inhelder, 1945/1968) e pode ser realizada a sós ou na companhia de pares ou adultos significativos para as crianças, nos mais diversos ambientes de seu cotidiano (Macedo, 2003). As crianças de idade préescolar são as que mais se engajam em brincadeira simbólica, mas ao final desse período, quando surgem os jogos com regras, a frequência com que as crianças brincam de faz de conta diminui (Piaget \& Inhelder, 1945/1968). Há evidências, no entanto, de que após a primeira infância, o faz de conta se torna mais privado e as crianças são mais propensas a se engajarem em fantasia quando estão sozinhas ou há poucos amigos presentes (Smith \& Lillard, 2012).

Segundo Macedo (2003), a brincadeira é a forma por excelência que a criança encontra para empregar significados ao mundo que a rodeia, vivenciando situações diversas, quantas vezes e da maneira como ela quiser. O faz de conta é entendido por muitos pesquisadores como o precursor de diversas capacidades cognitivas humanas, já que envolve a criação e a atuação de mundos imaginários (Lillard, 2007). Efetivamente, o faz de conta permite à criança ir muito além da diversão, já que, durante essa atividade aparentemente recreativa, há aprendizagem de habilidades importantes para a vida humana, tais como o monitoramento, a tomada de decisão, o revezamento, a reciprocidade, além de a criança exercitar o uso da linguagem e a interação social (Preissler, 2006).

Harris (2000) lembra que o faz de conta emerge ao mesmo tempo em que a linguagem. Nesse momento, as crianças já apresentam um entendimento limitado, mas funcional sobre o mundo que as cerca. É esse conhecimento que se manifesta na brincadeira simbólica infantil, em que as crianças procuram explorar as possibilidades da realidade - ainda que não realizem representações fiéis da mesma - por meio da construção de enredos coerentes e que possuem relações causais dentro de sua estrutura ficcional. $\mathrm{O}$ faz de conta está relacionado, ainda, ao pensamento contrafactual, já que a criança aprende a suspender o presente a fim de inventar e interagir com outra situação imaginada.

Finalmente, o faz de conta também tem sido relacionado por diversos autores ao desenvolvimento da teoria da mente (e.g., Alves, Dias, \& Sobral, 2007; Harris, 2000; Leslie, 1987). Diferentes estudos evidenciam que as crianças que se engajam mais em jogo de papéis são mais habilidosas em compreender estados mentais, apresentando melhores desempenhos em testes que exigem a apreciação da subjetividade de terceiros no que se refere a emoções, crenças e desejos (e.g., Taylor \& Carlson, 1997).

Em resumo, a brincadeira simbólica possibilita às crianças, por meio da imaginação, assumir diversos papéis e experimentar o mundo social de um modo ativo e dramático. Deste modo, elas trabalham emoções e compreendem o mundo no qual estão inseridas, ao verificarem as consequências dos seus atos e, assim, internalizarem as regras de conduta (Oliveira, Mello, Vitória, \& Rossetti-Ferreira, 1993). Como resultado, o faz de conta parece contribuir para o desenvolvimento cognitivo, em especial, para o pensamento abstrato e a criatividade (Harris, 2000). Para Harris, o faz de conta é a primeira indicação da capacidade mental de busca de alternativas à realidade, uma importante conquista que permanece durante toda a vida.

Entre as diversas formas que a brincadeira simbólica pode assumir, uma, no entanto, se destaca por suas características singulares: a criação de amigos imaginários. Embora os trabalhos pioneiros tenham tratado o fenômeno como raro e frequentemente encontrado em crianças com problemas emocionais ou de comportamento (e.g., Svendsen, 1934), a literatura mais recente atesta exatamente o contrário. Mais especificamente, há evidências de que os amigos imaginários são esperados na vida mental das crianças (cf. Taylor, 1999). A sua presença está inclusive relacionada a características positivas do desenvolvimento, tais como competência narrativa (Taylor, Cartwright, \& Carlson, 1993; Trionfi \& Reese, 2009), sociabilidade ou competência social (Gleason, 2002; Hoff, 2005a; Manosevitz, Prentice, \& Wilson, 1973) e uma cognição social mais avançada (Taylor \& Carlson, 1997).

No Brasil, vários pesquisadores têm explorado diferentes aspectos da brincadeira simbólica, por exemplo: (a) distinção entre realidade e fantasia no faz de conta (Dias, 1992); (b) a relação entre faz de conta e teoria da mente (e.g., Alves, Dias, \& Sobral, 2007; Sperb \& Carraro, 2008; Velludo, 2010). E embora a pesquisa brasileira sobre brincadeira simbólica tenha crescido muito nos últimos anos, há apenas dois registros de estudos nacionais investigando o fenômeno dos amigos imaginários (Bittencourt \& Blanco, 1996; Tavares \& Pinheiro, 1989). De forma semelhante, em outros países, o interesse pelo tema começou a crescer apenas mais recentemente, em especial, após a publicação dos estudos de Marjorie Taylor e seus colaboradores (e.g., Taylor, 1999; Taylor \& Carlson, 1997; Taylor et al., 1993).

Uma possível explicação para essa lacuna na literatura parece estar relacionada com concepções equivocadas sobre o papel do amigo imaginário no 
desenvolvimento infantil. Por exemplo, dados de um estudo nacional (Velludo, 2014) sugerem que muitos pais desencorajam a criação de amigos imaginários ou simplesmente não estão cientes de que seus filhos podem ter um. Uma das crianças participantes do estudo, por exemplo, relatou que o pai fingiu "matar" o amigo imaginário do filho, enquanto ela tentava protegê-lo. Várias crianças participantes solicitaram à pesquisadora que não contasse para ninguém (inclusive para os pais) que elas tinham um amigo imaginário. Alguns pais parecem não se importar com esse tipo de brincadeira, pois consideram que essa é apenas uma manifestação de imaginação e desconhecem as evidências de que o amigo imaginário pode estar associado a ganhos importantes no desenvolvimento infantil.

Em resumo, o fenômeno do amigo imaginário merece mais atenção por parte dos pais, educadores e pesquisadores interessados em desenvolvimento infantil. Além de mais pesquisas testando possíveis efeitos desse tipo de brincadeira simbólica sobre as crianças, é necessário também investir na divulgação dessas evidências mais recentes. O presente trabalho pretende contribuir nessa direção, apresentando uma revisão da literatura e, ao mesmo tempo, apontando direções futuras para essa linha de pesquisa no país. Mais especificamente, pretendeu-se oferecer uma revisão abrangente e histórica da literatura nacional e estrangeira sobre os amigos imaginários, enfocando a análise nos principais temas investigados e nos métodos utilizados, assim como nas correlações do fenômeno com aspectos positivos e negativos do desenvolvimento. Justifica-se o presente trabalho em função de não haver nenhum artigo brasileiro de revisão da literatura a respeito do assunto.

\section{MÉTODO}

A pesquisa bibliográfica sobre amigos imaginários foi realizada por meio da busca eletrônica de livros e artigos indexados nas seguintes bases de dados: SciELOBrasil, Index Psi, PePSIC, LILACS e PsycINFO. Os descritores utilizados foram as formas em singular e plural de "amigo imaginário" e seus correspondentes na língua inglesa ("imaginary companion" e "imaginary friend"). Apenas artigos, livros, capítulos de livro ou manual, plenamente acessíveis, nos idiomas português ou inglês, foram selecionados. Os critérios de inclusão adotados foram o tema ser pertinente à criação de amigos imaginários, além de dedicado à população de desenvolvimento típico. Adicionalmente, os critérios de exclusão de artigos foram: a) má qualidade (p. ex., baseado exclusivamente em postagens de fóruns online); b) metodologia de estudo de caso, já que esses trabalhos em geral incluem amostra clínica, dificultando a generalização dos resultados.

O período coberto foi relativamente extenso, de 1934 a 2013. Inicialmente, foram encontradas 145 referências potencialmente relevantes, sendo 141 na base PsycINFO, duas no LILACS e duas no Index Psi. Uma busca inicial nos resumos permitiu remover um artigo repetido, devido à reimpressão, assim como excluir aqueles trabalhos que não atendiam aos critérios de inclusão, chegando-se, assim, a 42 referências. Uma estratégia complementar empregada para a seleção de bibliografia relevante foi a busca nas referências dos artigos já selecionados para revisão. Assim, foram incluídos quatro trabalhos, sendo um artigo e três capítulos de livro. A Figura 1 ilustra o processo de busca e seleção de referências.

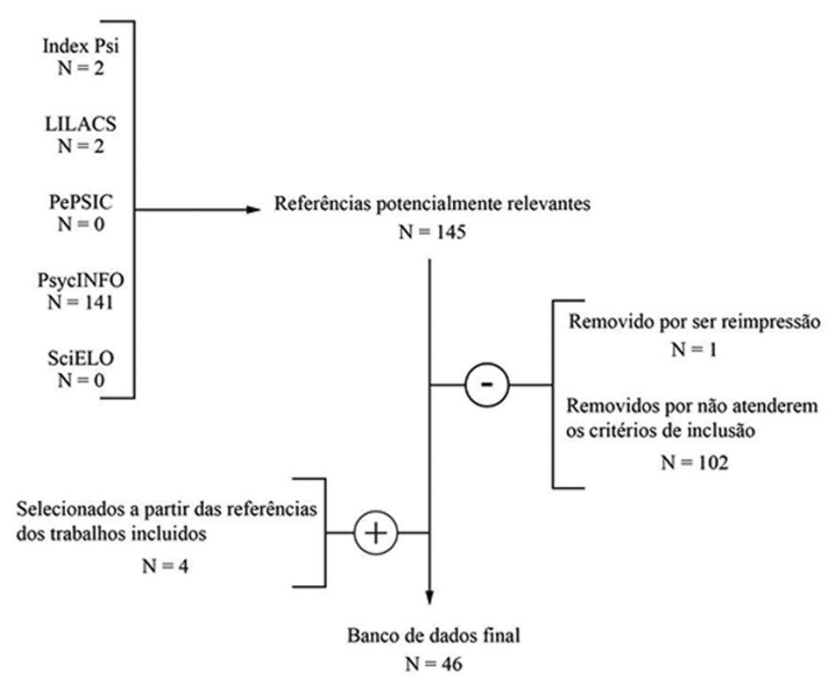

Figura 1. Ilustração do processo de busca e avaliação de referências, até o resultado final.

Deste modo, foram selecionadas 46 referências relevantes dedicadas ao tema. Dentre esses trabalhos, 31 são diretamente citados no presente artigo e destacados por asteriscos na lista de referências, enquanto os 15 trabalhos restantes contemplados são apresentados na Tabela 1. Apenas um trabalho nacional foi incluído, sendo este publicado em 1996. Por sua vez, a maior produção estrangeira se deu nos anos 2000, totalizando 28 trabalhos. Cabe dizer que, nos últimos 5 anos cobertos pela presente revisão (2009 a 2013), foram publicados nove trabalhos estrangeiros.

A fim de analisar as referências encontradas, foram utilizadas as seguintes dimensões e categorias: (a) origem (nacional ou estrangeira); (b) tipo de publicação (artigo, capítulo ou livro); (c) tipo de estudo (empírico ou revisão teórica); (d) técnica de coleta de dados 
TABELA 1

Trabalhos contemplados pela revisão e não citados, em ordem cronológica

\begin{tabular}{|c|c|}
\hline Autoria (Ano) & Tema \\
\hline Schaefer (1969) & Competência criativa de crianças com e sem amigos imaginários \\
\hline Meyer \& Tuber (1989) & Correlatos intrapsíquicos e comportamentais de crianças com amigos imaginários \\
\hline Taylor \& Carlson (2000) & $\begin{array}{l}\text { A influência de crenças religiosas nas atitudes parentais quanto a atividades fantasiosas e } \\
\text { amigos imaginários }\end{array}$ \\
\hline Pearson et al. (2001) & Prevalência do fenômeno na população e avaliação de criatividade \\
\hline Bouldin \& Pratt (2001) & Habilidade de crianças com amigos imaginários diferenciarem realidade e fantasia \\
\hline Coetzee \& Shute (2003) & $\begin{array}{l}\text { Avaliação da competência percebida por crianças com amigos imaginários e investigação } \\
\text { da influência dos estereótipos de gênero na construção desse faz de conta }\end{array}$ \\
\hline Gleason (2004a) & Aceitação social de crianças com amigos imaginários \\
\hline Gleason (2004b) & $\begin{array}{l}\text { Avaliação do relato parental como fonte de informação sobre o engajamento infantil em } \\
\text { fantasia }\end{array}$ \\
\hline Gleason (2005) & Atitudes parentais quanto à fantasia infantil \\
\hline Mathur \& Smith (2007) & Natureza do fenômeno em relação à idade e etnia \\
\hline Taylor, Carlson, \& Shawber (2008) & Senso de autonomia e controle das crianças sobre seus amigos imaginários \\
\hline Taylor, Hulette, \& Dishion (2010) & $\begin{array}{l}\text { Avaliação de possíveis correlatos negativos da criação de amigos imaginários (medo, } \\
\text { ansiedade, personalidade, entre outros) em uma amostra de risco socioeconômico }\end{array}$ \\
\hline Honeycutt, Pecchioni, Keaton, \& Pence (2011) & $\begin{array}{l}\text { Implicações no desenvolvimento de "imagery" mental associada à criação de amigos } \\
\text { imaginários }\end{array}$ \\
\hline Majors (2013) & $\begin{array}{l}\text { As características e funções dos amigos imaginários, a partir da perspectiva das crianças } \\
\text { que os criam }\end{array}$ \\
\hline Wigger, Paxson, \& Ryan (2013) & $\begin{array}{l}\text { Avaliação da atribuição de conhecimento a diferentes entidades (ser humano, cão, amigo } \\
\text { imaginário e Deus) por crianças que possuem companhias de faz de conta }\end{array}$ \\
\hline
\end{tabular}

(entrevista, questionário, escala, teste psicométrico, dentre outros); (e) tamanho da amostra; (f) participantes do estudo (pai/mãe, criança, adolescente, adulto); (g) tema investigado (e.g., associações com teoria da mente e cognição social, fantasia e imaginação, dentre outros); (h) perspectiva teórica (e.g., cognitiva); (i) grupo de comparação (presença ou não).

Dois juízes realizaram a busca e a avaliação dos artigos. Uma primeira busca foi realizada em dezembro de 2013, no entanto, de forma a manter o manuscrito atualizado, uma segunda busca foi feita em agosto de 2014. A avaliação foi feita no mesmo intervalo de tempo, por ambos os juízes. Quando necessário, os juízes discutiam até chegarem a um consenso a respeito da seleção de referências, respeitando os critérios pré-estabelecidos. Os modelos utilizados para análise foram: (a) metodologia e (b) fatores de risco e/ ou prevenção.

\section{RESULTADOS E DISCUSSÃO}

De todos os trabalhos considerados para análise, houve apenas um nacional e 48 referências estrangeiras. Quanto ao país de origem dos trabalhos estrangeiros, a maioria absoluta era proveniente dos $\operatorname{EUA}(66,6 \%)$, seguida por Austrália (13,3\%), Reino Unido (8,8\%), Suécia (4,4\%), Alemanha e Nova Zelândia, igualmente frequentes $(2,2 \%)$, e finalmente, estudo internacional (2,2\%), com pesquisadores da Austrália e do Reino Unido. É notável a consolidação dos EUA como o país mais produtivo na área, assim como o crescente interesse pelo assunto por pesquisadores da Europa e da Oceania. De todo modo, não foram encontradas pesquisas realizadas em países da América Latina, Ásia ou África. O único esforço nesse sentido é o capítulo teórico de Taylor e Carlson (2000), que aborda crenças religiosas e culturais acerca de amizades imaginárias em países diversos, como a Índia.

Quanto ao tipo de publicação, a brasileira era artigo. Por sua vez, entre os trabalhos estrangeiros, a maioria era artigo $(84,4 \%)$, alguns eram capítulos de livro ou manual $(13,3 \%)$ e havia um livro dedicado ao tema $(2,2 \%)$. Em relação ao tipo dos estudos internacionais, $86,7 \%$ eram empíricos e $13,3 \%$ eram teóricos ou revisões de literatura.

Em relação à técnica de coleta de dados utilizada, o estudo brasileiro se valeu apenas de questionário. Nos estudos estrangeiros, por sua vez, há uma prevalência de entrevista como técnica mais utilizada $(65,8 \%)$, seguida por questionário $(36,8 \%)$, teste psicométrico 
(31,6\%), escala $(23,7 \%)$ e inventário $(18,4 \%)$. Com uma menor frequência, também foram utilizados tarefas $(15,8 \%)$, respostas não verbais/medidas comportamentais $(13,2 \%)$, respostas verbais $(10,5 \%)$, relato de pais ou professores $(7,9 \%)$ e, mais raramente, checklist $(5,3 \%)$. Cabe ressaltar que a maioria dos estudos (72\%) utilizou mais de uma técnica de coleta de dados, motivo pelo qual o total ultrapassa o número de estudos empíricos. Essa combinação de medidas é em parte justificada pela necessidade de avaliação dos participantes para determinar se pertencem ao grupo de interesse (e.g., crianças com amigos imaginários), que, em geral, é feita via entrevista ou questionário.

Os participantes do estudo brasileiros foram mães de crianças pré-escolares. Em relação aos participantes, a maioria dos estudos estrangeiros contou com crianças pré-escolares $(31,6 \%)$, seguido daqueles trabalhos com pré-escolares e escolares $(18,4 \%)$, mães e/ou pais $(10,5 \%)$. Igualmente menos frequentes $(7,9 \%)$ foram estudos com escolares, pré-escolares e seus pais, assim como crianças em diferentes idades. Finalmente, e com a mesma frequência $(5,3 \%)$ foram estudos com escolares e adolescentes, apenas adolescentes, e com jovens universitários. O fato de estudos com crianças menores serem os mais recorrentes, pode ser explicado pelo fato de a literatura tender a limitar o fenômeno à pré-escola. Estudos com crianças em idade escolar foram importantes por demonstrar que mesmo crianças mais velhas criam amigos imaginários (e.g., Hoff, 2005a), assim como adolescentes (e.g., SeiffgeKrenke, 1997).

Quanto ao tamanho da amostra, o trabalho nacional contou com 100 participantes. Por sua vez, entre os estudos estrangeiros, a menor amostra contou com oito participantes e, a maior, com 1800 . Na maioria dos trabalhos $(39,5 \%)$, o número de participantes variou entre 51 e 100, seguida por aqueles com até 50 sujeitos $(23,7 \%)$ e daqueles estudos demográficos, com mais de 200 participantes $(15,8 \%)$. Portanto, embora haja uma grande variação, a tendência da maioria dos estudos sobre o fenômeno é a prevalência de amostras com até uma centena de participantes $(63,2 \%)$.

A análise dos temas investigados evidencia que o trabalho brasileiro se dedicou à percepção de mães sobre a criação de amigos imaginários. Por sua vez, os temas dos trabalhos internacionais, são: (a) associações com outras habilidades cognitivas, sociais, aspectos psicológicos e traços de personalidade (28,8\%); (b) revisão de literatura ou trabalho teórico sobre o fenômeno (15,6\%); (c) fantasia e imaginação $(11,1 \%)$; (d) associações com teoria da mente e cognição social (11,1\%); (e) natureza e função de amigos imaginários (8,8\%); (f) associações com transtornos ou aspectos negativos $(8,8 \%)$; $(\mathrm{g})$ prevalência do fenômeno na população e fatores individuais e/ou ambientais associados $(6,6 \%)$; (h) percepção de crianças sobre suas amizades imaginárias e relações sociais $(4,4 \%)$; (i) relato parental e percepção de pais sobre amigos imaginários (4,4\%). Destacam-se, portanto, os estudos que investigam correlações do fenômeno com habilidades cognitivas, como criatividade e competência social, por exemplo, ou traços de personalidade, como timidez.

A análise das perspectivas teóricas permite inferir que o estudo brasileiro adota a teoria cognitivista. Quanto aos trabalhos internacionais, é possível concluir que a maioria absoluta foi conduzida por psicólogos do desenvolvimento interessados em desenvolvimento cognitivo, ou sociocognitivo, enquanto apenas cinco foram realizados por psicólogos clínicos ou do desenvolvimento de abordagem psicodinâmica.

Quanto à presença de grupo de comparação, a maioria absoluta $(86,8 \%)$ dos estudos estrangeiros contou com uma amostra de crianças que não se engajava na criação de amigos imaginários. De fato, o emprego do grupo de comparação possibilita um maior rigor metodológico, ainda que não signifique que aqueles que não contaram com o mesmo sejam deficitários, pois a questão de pesquisa nem sempre exige esse cuidado - por exemplo, estudos sobre a natureza e a função de amigos imaginários para as crianças que os criam. Por sua vez, o estudo brasileiro não teve grupo de comparação, uma vez que foi realizado com mães de pré-escolares.

As sessões seguintes sumarizam os achados principais sobre o que define o fenômeno da criação de amigos imaginários, qual a sua incidência na população e as características positivas e negativas do desenvolvimento que têm sido associadas à sua presença.

\section{CARACTERÍSTICAS E FUNÇÕES DOS AMIGOS IMAGINÁRIOS}

No mesmo período em que as crianças normalmente já brincam de jogo de papéis, entre os 2 e os 3 anos, algumas começam a criar amigos imaginários. As características que definem essa peculiar fantasia é o jogo de papéis com uma pessoa ou criatura imaginária, cuja identidade permanece estável por vários meses. $\mathrm{O}$ personagem é invocado tão regularmente no cotidiano da criança que ele se torna um tipo de companhia para ela (Harris, 2000).

A invenção de amigos imaginários pode ser a resposta adaptativa de uma criança que esteja lidando com dificuldades em sua vida, já que a fantasia permite 
que ela lide com problemas emocionais e, em especial, medos (Taylor, 1999). No entanto, esta é apenas uma das diferentes e possíveis funções dos amigos imaginários. Por exemplo, ao longo de uma série de estudos, Taylor e colaboradores compilaram mais de 340 descrições de amigos imaginários que ilustram a variedade de usos desse tipo de faz de conta:

Além de fornecer diversão e companhia quando ninguém mais está disponível, eles podem aguentar o impacto da raiva da criança, serem culpados pelos maus feitos, fornecerem um ponto de referência quando precisam barganhar com os pais (e.g., 'Se BlaBla não tem que terminar de comer seu jantar, por que é que eu tenho?'), ou servir como um veículo para comunicar informação quando a criança reluta em dizer diretamente (e.g., 'O Sr. Ninguém está com medo do novo cão do vizinho'). (Taylor \& Carlson, 2002, p. 178)

Os pais de pré-escolares, de um modo geral, costumam ter ciência da existência de tais companhias imaginárias, já que as próprias crianças produzem relatos frequentes sobre os seus amigos, fazendo com que haja interação em torno desse faz de conta elaborado e duradouro. O mesmo não pode ser dito sobre pais de crianças mais velhas que possuem amigos imaginários, já que essas nem sempre tornam público o seu faz de conta (Taylor, 1999).

Gleason e colaboradores sugerem que o relacionamento com amigos imaginários pode atuar de modo similar a amizades reais de alta qualidade, gerando iniciativas de cuidado e atenção direcionados a eles, por parte da criança (Gleason, 2002; Gleason, Sebanc, \& Hartup, 2000). De fato, a amizade infantil baseia-se em afeto, companheirismo e brincadeiras (Bukowski, Newcomb, \& Hartup, 1996), características igualmente presentes em sua versão imaginária (e.g., Taylor, 1999). A amizade é considerada um contexto importante para o desenvolvimento emocional, social e cognitivo infantil (Bukowski et al., 1996), o que a literatura brasileira também tem indicado (e.g., Piotto \& Rubiano, 1999).

No Brasil, o tema das amizades infantis tem despertado um interesse crescente de pesquisadores, $\mathrm{o}$ que se deve, em parte, às contribuições da Psicologia Positiva (cf. Lisboa, 2012). Silva e Garcia (2008), por exemplo, sugerem que as primeiras manifestações de amizade, em torno dos 18 meses, ocorrem sob forte influência parental, via facilitação de encontros com pares e apresentação de padrões socioculturais. Por sua vez, Piotto e Rubiano (1999) demonstram que já há diferenças nos padrões de interação estabelecidos por pares na creche, ou seja, algumas crianças são preferidas, outras são neutras e algumas são preteridas.

Daudt, Souza e Sperb (2012), por sua vez, argumentam que, ao interagir com amigos, crianças em idade escolar apresentam desempenhos muito mais competentes socialmente do que com não amigos. Ainda, há uma diferença de gênero significava, já que ser menina está relacionado a comportamentos socialmente dirigidos, não importando o tipo de relação - o que só ocorre no contexto de amizade, para os meninos. Finalmente, Lisboa (2012) destaca a reciprocidade como fator protetivo em amizades infantis nas quais características individuais de risco (agressividade, isolamento ativo ou competência escolar) são apresentadas e, assim, relativiza a máxima de que tais relacionamentos sejam sempre benéficos, pois pode haver desfechos opostos (vitimização ou não) em relação ao grupo social em que o par se insere.

Em contraste às amizades reais, as companhias imaginárias não são agentes independentes, dotados de cognição própria, mas também exercem diversas funções positivas comprovadas, como por exemplo, auxiliar na elaboração de aspectos dos relacionamentos reais e oferecer uma oportunidade de ensaio de interações sociais (Gleason, 2002).

$\mathrm{O}$ fato de as crianças se mostrarem absorvidas e emocionalmente envolvidas com suas criações não indica que as crianças estejam confundindo realidade e fantasia. Taylor, Shawber e Mannering (2009) argumentam que as crianças têm plena noção de que seus amigos imaginários são de faz de conta, inclusive explicitamente definindo-os assim. Em um dos estudos conduzidos no laboratório de Taylor com mais de 80 crianças, 97\% delas indicavam estar conscientes de se tratar de uma criação fruto de sua mente (Taylor \& Mottweiler, 2008).

As características dos amigos imaginários são também muito variadas. Enquanto algumas crianças possuem apenas uma companhia imaginária, é comum que outras possuam duas ou mais, ao mesmo tempo. Quanto à estabilidade, há casos em que a criança constantemente muda de amigos, transitando entre algumas entidades de faz de conta, de duração reduzida, mas há também criações que se mantém ao longo de anos, como os curiosos relatos de amigos imaginários que passam de geração para geração, como um legado de fantasia familiar (Taylor, 1999).

A maioria dos pesquisadores interessados em amigos imaginários trata os casos de personificação, no entanto, como um fenômeno à parte (e.g., Bouldin, 2006; Hoff, 2005a; Taylor, 1999; Taylor \& Carlson, 1997). Nesse faz de conta elaborado, a criança simula que ela própria é outra pessoa, animal ou criatura 
inventada, regularmente, não havendo uma entidade independente que configure uma companhia imaginária. De qualquer modo, a personificação é um faz de conta muito próximo à criação de amigos imaginários.

Se os casos de personificação forem considerados à parte, os amigos imaginários ficam então limitados a dois contextos: (a) aquele em que o amigo imaginário é totalmente independente de base material, não ocorrendo projeção objetiva; e (b) aquele em que há projeção sobre objetos de apoio, tais como brinquedos especiais para a criança, ou mesmo inusitados, como a imagem da própria criança refletida no espelho, partes do corpo, ou até folhas de árvore (Taylor, 1999).

Os estudos seminais sobre o assunto restringiam os amigos imaginários àquelas criações que não contavam com nenhum suporte físico. Margaret Svendsen (1934), por exemplo, define os amigos imaginários como criaturas invisíveis, com os quais a crianças brincam por vários meses, que são nomeados e relatados em conversas com outras pessoas, a ponto de adquirirem certo ar de realidade.

Taylor (1999) considera não haver motivo para, a priori, serem excluídos os casos em que há projeção em objetos de apoio. Um dos argumentos utilizados contra a projeção é o de que os objetos de apoio são reais e, portanto, possuem uma aparência física que independe da imaginação da criança. No entanto, ainda que um amigo imaginário parta de um objeto real, a entidade criada costuma extrapolar o seu aspecto físico - como pode ser exemplificado pelo cartum de Bill Watterson: o garoto Calvin possui um amigo imaginário, Haroldo, um tigre muito grande na sua imaginação, que é muito diferente do pequeno tigre de pelúcia que sempre o acompanha. Além disso, as crianças não são totalmente dependentes dos objetos palpáveis, já que ora interagem com a criação de um modo absolutamente independente, ora voltam-se para o apoio, em uma livre transição.

A inclusão de bichos de pelúcia e bonecos na categoria de objeto de apoio, no entanto, gera um problema prático, que é diferenciar brinquedos preferidos, com os quais a criança brinca frequentemente, daqueles que realmente dão suporte a amigos imaginários (Taylor, 1999). A autora sugere que a invenção de um amigo invisível possivelmente não seja o mesmo que criar uma personalidade para um brinquedo favorito, no entanto, a maioria dos pesquisadores utiliza critérios em que brinquedos que adquirem características especiais são incluídos.

A existência de diferenças na definição de amigos imaginários acaba levando a uma grande variação nos indicadores da incidência do fenômeno na população infantil. No estudo de Svendsen (1934), com uma amostra de 111 crianças de 3 a 16 anos, apenas $13,4 \%$ foram identificadas como criadoras de amigos imaginários. O critério escolhido pela pesquisadora foi o de incluir apenas criaturas imaginárias sem qualquer suporte físico. Setenta anos depois, Gleason e Hohmann (2006) encontraram uma porcentagem um pouco maior: $26 \%$ de uma amostra de 84 crianças entre 3 e 5 anos de idade possuíam amigos imaginários com ou sem projeção em objetos de apoio.

Harris (2000) sugere que, se consideradas as três formas de criação de jogo de papéis, esse número aumentaria ainda mais, atingindo até três quartos das crianças. De fato, Singer e Singer (1990, citado por Taylor, 1999), utilizando uma definição mais abrangente, encontraram uma incidência bem mais alta: $65 \%$ das crianças de sua amostra declararam criar criaturas imaginárias. Dados mais recentes também apresentam estimativas mais generosas. Carlson e Taylor (2005), por exemplo, identificaram que $40 \%$ das meninas e $37 \%$ dos meninos criavam companhias imaginárias, apenas personificando ou se engajando em ambos os tipos de fantasia.

Já no estudo longitudinal de Taylor, Carlson, Maring, Gerow e Charley (2004), 100 crianças que haviam participado do estudo de Taylor e Carlson (1997) foram entrevistadas novamente sobre o engajamento em faz de conta, três anos depois. Em idade pré-escolar, $28 \%$ das crianças relataram possuir amigos imaginários ou personificavam. Os dados desse estudo mais recente, no entanto, indicaram que $31 \%$ das crianças entre os 6 e os 7 anos estavam se engajando na criação de amigos imaginários, mas $65 \%$ das crianças haviam criado tais companhias até os 7 anos.

Como pode ser observado, determinar a prevalência do fenômeno na população infantil é uma tarefa difícil, em especial, por que cada estudo adota critérios distintos para a seleção dos participantes. Além disso, ainda não há consenso entre os pesquisadores sobre quais são os melhores critérios para se identificar crianças com amigos imaginários.

Os pais não são considerados fontes muito confiáveis de informação, já que há discrepâncias entre o discurso parental e o de seus filhos (Taylor, 1999). Além disso, eles não costumam saber muitos detalhes sobre os amigos imaginários, o que pode ser explicado, em geral, por dois motivos. Em primeiro lugar, embora alguns pais digam que se sentem confortáveis com o fato de seus filhos terem companhias imaginárias, eles relutam em buscar informações, já que não querem incentivar tais fantasias, em especial, porque acreditam que elas manifestam problemas emocionais ou uma dificuldade para distinguir fantasia e realidade. Além disso, há pais que simplesmente ignoram a existência 
desses amigos especiais, pois a criança provê descrições tão realistas que os pais efetivamente acreditam se tratar de alguém real e não de uma criação de faz de conta (Taylor, 1999; Taylor \& Mannering, 2006).

Em um estudo baseado exclusivamente em relatos parentais, Manosevitz et al. (1973) entrevistaram pais de 222 crianças com idades entre 3 e 5 anos, e apenas $28 \%$ delas foram indicadas como possuindo amigos imaginários. Segundo Taylor (1999), estimativas baseadas em relatos dos pais tendem a ser baixas, devido às limitações anteriormente apresentadas. Ainda assim, pais podem ser importantes em estudos sobre o fenômeno, já que proveem informações que as crianças não possuem, tal como a época do surgimento do amigo imaginário, por exemplo.

Outro procedimento possível é o de obter relatos de adolescentes ou adultos sobre os seus amigos imaginários da infância, como foi feito por Gleason, Jarudi e Cheek (2003), com uma amostra de universitárias. O relato das próprias crianças, no entanto, é considerado por muitos como a melhor fonte de informação sobre os amigos imaginários, uma vez que os mesmos são fruto da sua própria imaginação e fazem parte da sua experiência atual, não passada (e.g., Taylor, 1999). Ainda assim, é necessário tomar alguns cuidados com o modo pelo qual o pesquisador aborda a questão, a fim de assegurar que se trata de uma criação de faz de conta, nos moldes de um amigo imaginário. As crianças podem, por exemplo, prover a descrição de um amigo real, ou mesmo, se sentirem convidadas a inventarem um durante a coleta de dados.

Preocupados em desenvolver um método que possibilitasse explorar o fenômeno dos amigos imaginários de modo confiável, Taylor et al. (1993) pediram aos participantes que utilizassem um telefone de brinquedo para convidarem seus amigos a virem para a sala experimental. Assim, descobriram que as crianças estão dispostas a produzir relatos sobre suas companhias de faz de conta e até mesmo a interagir com as mesmas durante as sessões experimentais.

Em um estudo posterior, Taylor e Carlson (1997) utilizaram o procedimento de entrevistar tanto as crianças como os seus pais sobre os amigos imaginários, separadamente, e em dois momentos diferentes, com um intervalo de uma semana entre as entrevistas. Deste modo, foi possível avaliar a consistência das respostas, ou seja, verificar se as respostas de ambos eram mantidas em um momento posterior, se os relatos de pais e filhos se corroboravam, além de obter esclarecimentos necessários. Talvez a solução para o problema da variabilidade de critérios para a seleção dos participantes seja exatamente esta: contrastar relatos provenientes de diferentes fontes (pais, crianças) e em diferentes momentos e, assim, obter uma amostra representativa e relatos confiáveis.

\section{A CRIANÇA QUE POSSUI AMIGOS IMAGINÁRIOS}

Quem é, afinal, a criança que possui amigos imaginários? Os primeiros estudiosos sobre o assunto entendiam que a persistência com que as crianças com amigos imaginários ficam imersas em fantasia poderia predizer distúrbios emocionais e sociais (cf. Taylor \& Mottweiler, 2008). Svendsen (1934), por exemplo, afirmou que a maioria das crianças que criava amigos imaginários possuía problemas de personalidade, tais como timidez e comportamento dominador em relação a seus pares. No geral, tais estudos precisam ser avaliados com cautela, porque apresentam problemas metodológicos. O primeiro é a ausência de grupo controle e o segundo é a seleção de amostras não aleatórias, recrutadas em clínicas ou centros de apoio a crianças, populações que têm um risco aumentado de apresentar problemas de personalidade (Harris, 2000; Taylor, 1999).

Estudos mais recentes sugerem um quadro mais favorável em relação aos amigos imaginários e a sua associação com aspectos positivos do desenvolvimento. Por exemplo, já há evidências de que as crianças que possuem amigos imaginários possuem uma vida de fantasia mais rica que seus pares que não desenvolvem tais criações (e.g., Bouldin, 2006; Taylor et al., 1993). Além de se engajarem frequentemente em faz de conta, tais crianças tendem a inserir figuras míticas (por exemplo, Papai Noel) em suas brincadeiras e a explicar eventos por meio de mágica (Bouldin \& Pratt, 1999).

Bouldin, Bavin e Pratt (2002), por sua vez, avaliaram as habilidades verbais de 80 crianças australianas, entre 4 e 8 anos, sendo que metade delas possuía companhias imaginárias. Os resultados indicaram que o grupo com amigos imaginários apresentava linguagem mais desenvolvida que o outro grupo, por exemplo, essas crianças faziam uso mais frequente de orações adverbiais e adjetivas, conjunções e verbos auxiliares. Em um estudo sobre competência narrativa realizado com crianças de 5 anos, as crianças com e sem amigos imaginários possuíam níveis de vocabulário semelhantes, mas a criação de amigos imaginários estava associada à produção de narrativas mais ricas, tanto sobre experiências pessoais, quanto sobre um livro (Trionfi \& Reese, 2009).

Roby e Kidd (2008) se interessaram, por sua vez, em investigar se há alguma vantagem para crianças com amigos imaginários em um domínio em que tanto a competência comunicativa quanto a tomada de 
perspectiva são requeridas: a comunicação referencial. As habilidades comunicativas referenciais dizem respeito à codificação e decodificação de informação verbal. Para tanto, os pesquisadores contaram com uma amostra de 44 participantes entre 4 e 6 anos, sendo que metade deles possuía amigos imaginários. Em uma das tarefas que avaliavam essas habilidades, a fim de obter sucesso, a criança tinha que levar em consideração dois atributos específicos da imagem que a diferia das outras, por exemplo, que um palhaço tinha o colarinho verde e usava uma cartola. Nessa tarefa, as crianças que possuíam amigos imaginários se mostraram mais habilidosas para decodificar e avaliar a informação oferecida pelo experimentador, bem como usá-la adequadamente.

Ainda dentro do domínio da linguagem, alguns pesquisadores têm se interessado por pesquisar a fala privada (falar sozinho ou internamente) de indivíduos que criam amigos imaginários e as características potencialmente relacionadas à frequência desse "falar consigo". Fernyhough, Bland, Meins e Coltheart (2007) descobriram que o grupo de crianças que criava tais companhias era mais propenso a interpretar estímulos auditivos ambíguos e sem sentido como sendo palavras. Para os autores, tal achado evidencia que tais crianças têm uma susceptibilidade geral a experiências verbais imaginárias.

Considerando que tal susceptibilidade poderia estar associada a altos níveis de fala interna, Davis, Meins e Fernyhough (2013) observaram crianças de 5 anos durante períodos de brincadeira livre, a fim de descobrir se haveria uma relação entre status de amigo imaginário e esse falar privado. Controlando nível socioeconômico, linguagem receptiva e quantidade de expressões (utterances), as crianças com companhias imaginárias apresentaram uma tendência maior de se engajarem em fala do tipo encoberto (sussurros ou movimentos de lábios acompanhados por sons ininteligíveis) e, consequentemente, demonstraram uma fala privada mais internalizada - portanto, mais desenvolvida que a de seus pares que não se engajavam nesse tipo de fantasia.

Por sua vez, Brinthaupt e Dove (2012) investigaram se ter amigos imaginários na infância se associaria a uma maior frequência de fala interna na vida adulta. Em especial, os autores esperavam que tais adultos se engajassem em mais falas internas relativas à gestão de atividades cotidianas e relações sociais - o que refletiria maior capacidade de autorregulação e orientação social. Os resultados indicaram que os universitários que haviam criado amigos imaginários na infância relataram uma maior frequência de fala interna geral, assim como nos subitens autorreforçamento e autogestão, mas não diferiam do outro grupo quanto à autocrítica e à avaliação social (i.e., utilizar a fala privada para refletir sobre uma conversa ou discussão com um amigo e avaliar se algo inapropriado foi dito).

Em uma direção diferente, Hoff (2005b) avaliou a relação entre ter amigos imaginários e a criatividade em um estudo com 69 crianças suecas de 10 anos. As crianças com amigos imaginários apresentaram pontuações significativamente maiores em duas das três medidas de criatividade (questionário sobre envolvimento em atividades criativas e hobbies, e teste sobre fluência de ideias). Ainda assim, as mesmas apresentaram escores menores que o grupo de comparação na medida de autoimagem, sendo que tais diferenças eram maiores nos subtestes de bem-estar psicológico e relacionamento com pares e outros.

Taylor e Carlson (1997), por sua vez, investigaram a relação entre o universo de fantasia dos participantes e o desenvolvimento da teoria da mente em 152 crianças de 3 e 4 anos, de ambos os sexos. As diferenças individuais em fantasia foram medidas por meio de: (a) identificação da criação de amigos imaginários e personificação e (b) pontuação obtida em fatores derivados de uma combinação de entrevistas e medidas comportamentais (e.g., engajamento em fantasia imaginativa, escolha de brinquedo, realização de ações de faz de conta). Para as crianças de 4 anos, cada medida de fantasia estava significativamente relacionada com o desempenho em testes padrão de teoria da mente, independentemente de inteligência verbal.

Tal associação, no entanto, não é consensual. Mais recentemente, Davis, Meins e Fernyhough (2011) não encontraram uma correlação significativa entre o desempenho em tarefas de teoria da mente e status em relação a amigos imaginários (ter ou não). Por outro lado, o status estava correlacionado ao autoconhecimento interior das crianças, ou seja, as crianças com amigos imaginários se consideravam melhores juízes do que outros adultos em relação ao que acontecia internamente com as mesmas (e.g., os seus sonhos, pensamentos, desejos ou sensações).

Na mesma direção, Fernyhough et al. (2007) apresentam dados sugerindo não haver relação entre as variáveis teoria da mente e status de amigo imaginário. No entanto, os próprios pesquisadores reconhecem que a ausência da correlação pode ser explicada pelo fato de que eles não utilizaram uma tarefa padrão de teoria da mente. A tarefa utilizada avaliava a habilidade de a criança compreender que o pensamento (a consciência) permanece, mesmo na ausência de dicas perceptuais externas (Stream of Consciousness Task). 
Outra pergunta relevante sobre a caracterização das crianças com amigos imaginários diz respeito a possíveis diferenças de gênero. No estudo de Brinthaupt e Dove (2012) com jovens universitários, as estudantes do sexo feminino tinham uma probabilidade duas vezes maior de relatar um histórico de amigos imaginários (34\%) em comparação com os estudantes do sexo masculino (17\%). No entanto, essa diferença não é necessariamente resultado de uma prevalência maior de amigos imaginários entre meninas, em especial, porque a diferença se refere à frequência de relatos.

De fato, os resultados de Carlson e Taylor (2005) sugerem que a única diferença de gênero encontrada é que as meninas tendem mais a criar amigos imaginários, enquanto os meninos tendem a personificar mais os personagens. Por outro lado, os resultados de Harter e Chao (1992) sugerem que a função principal dos amigos imaginários pode variar de acordo com o gênero. Os meninos criam amigos imaginários que são mais competentes do que eles mesmos, ou seja, eles funcionariam como um ego ideal com quem eles podem se identificar. As meninas, no entanto, criam amigos imaginários menos competentes que, por sua vez, podem ajudar a aumentar a autoestima das mesmas e fortalecer seu senso de competência.

Alguns estudos indicam ainda que as crianças que criam amigos imaginários tendem a ser o primeiro filho da família, deste modo, a ordem de nascimento, aliada à propensão a se engajar em fantasia espontaneamente são fortes preditores da criação dos amigos imaginários (Bouldin \& Pratt, 1999; Manosevitz et al., 1973). Há, no entanto, poucas evidências consistentes de diferenças de personalidade ou temperamento entre as crianças que inventam amigos imaginários e as que não o fazem (Taylor, 1999). Algumas pesquisas indicam que indivíduos que criam tais companhias imaginárias tendem a ser sociáveis ao longo da vida. Durante a infância, eles interagem positivamente com adultos e se engajam em mais atividades com membros da família do que as outras crianças (Manosevitz et al., 1973), assim como demonstram uma preocupação constante em atender às expectativas de adultos (Bouldin \& Pratt, 2002).

É interessante observar como, na adolescência, outros mecanismos podem ser utilizados para preencher a função exercida pelos amigos imaginários na infância. Seiffge-Krenke (1997), por exemplo, descobriu que $40 \%$ de uma amostra de 241 adolescentes possuíam diários. Para um terço dos meninos e $60 \%$ das meninas, esses diários assumiam a função dos amigos imaginários, na medida em que os relatos eram endereçados a interlocutores que não existiam na vida real. Os dados desse estudo sugerem que a invenção dessas companhias especiais na adolescência está presente em jovens socialmente competentes, criativos e que possuem boas habilidades de enfrentamento.

Em outro estudo com estudantes universitárias entre 18 e 21 anos, Gleason et al. (2003) encontraram algumas correlações interessantes: as participantes que relataram ter criado companhias imaginárias durante a infância obtiveram pontuações maiores em imaginação e demonstraram ter maior consciência de estados internos e serem mais sociáveis do que as estudantes que não relataram ter possuído amigos imaginários. Nenhuma diferença, no entanto, foi encontrada em relação ao nível de timidez, medidas de autoconceito ou outros estilos interpessoais. Os autores concluíram que os seus dados corroboram estudos que relacionam os amigos imaginários à sociabilidade e, em especial, à sensibilidade e acomodação às necessidades dos outros.

Bouldin e Pratt (2002), por sua vez, investigaram se a criação de amigos imaginários estaria relacionada a medos específicos, níveis de ansiedade e características de temperamento. Os pesquisadores contaram com os relatos de 74 mães de crianças de 3 a 8 anos de idade, sendo que metade delas possuía ou havia tido amigos imaginários anteriormente. Os dados sugerem que o nível de ansiedade percebida foi significativamente maior para as crianças que inventavam tais companhias, no entanto, os escores obtidos se encontravam dentro da média esperada para a idade.

Partindo da sugestão presente na literatura psicológica de que haveria uma relação entre o jogo de papéis e dissociação, Carlson, Tahiroglu e Taylor (2008) investigaram essa possibilidade em uma amostra não-clínica de 147 crianças de idade pré-escolar. Os dados indicaram que as crianças que se engajavam em jogo de papéis (personificação ou amigos imaginários) e, em especial, aquelas que criavam companhias imaginárias, apresentavam maiores pontuações na medida de dissociação. Ainda assim, o jogo de papéis não se associou a medidas de medo ou problemas de comportamento. Deste modo, as autoras sugerem haver uma distinção entre dissociação patológica e não patológica.

Alguns dados de pesquisa indicam as possíveis desvantagens das crianças que possuem amigos imaginários. Alguns estudos sugerem que as crianças que criam amigos imaginários são menos sociáveis (Bouldin \& Pratt, 1999), mais ansiosas (Bouldin \& Pratt, 2002), além de serem menos competentes e apresentarem menores níveis de aceitação social por pares (Harter \& Chao, 1992) do que crianças que não têm amigos imaginários. Ainda assim, é importante notar que os três estudos contam apenas com o relato 
de figuras adultas próximas da criança (pais e professores). E, apesar dessas poucas evidências contrárias, a grande maioria dos estudos já realizados sugere que a criação dos amigos imaginários contribui positivamente e de diferentes formas para o desenvolvimento infantil.

\section{CONSIDERAÇÕES FINAIS}

O presente artigo pretendeu realizar uma revisão sistemática da literatura nacional e estrangeira sobre a criação de amigos imaginários, focalizando a análise sobre os temas mais investigados e os métodos utilizados nas pesquisas, de modo a possibilitar um quadro geral da produção científica relativa ao assunto. Além disso, pretendeu sumarizar os achados principais sobre a área. Os estudos demonstram que a criação de amigos imaginários, enquanto uma clara manifestação de fantasia e brincadeira simbólica, é associada a aspectos muito positivos do desenvolvimento, por exemplo, uma compreensão social sofisticada (Taylor \& Carlson, 1997), espírito criativo (e.g., Hoff, 2005b) e maior competência social (Manosevitz et al., 1973).

De modo geral, percebe-se que houve aumento dos estudos na área a partir da década de 1990, com uma acentuação significativa na produção nos anos 2000 - tendência que se espera que seja mantida na década atual. Entretanto, a criação de amigos imaginários ainda tem sido explorada de forma restrita na literatura psicológica e psiquiátrica estrangeira (SeiffgeKrenke, 1997) e incipiente no país, de modo que mais pesquisas são necessárias para que esse fenômeno seja plenamente compreendido. Mais especificamente, ainda há questões importantes sobre quem são as crianças que criam amigos imaginários e sobre o papel da fantasia no desenvolvimento emocional e cognitivo infantil (Taylor et al., 1993).
Considerando a literatura psicológica analisada, algumas direções futuras de pesquisa podem ser apontadas. Primeiramente, como os estudos têm se centrado em poucos países, é importante que variáveis como prevalência na população, natureza e funções do fenômeno, assim como as atitudes parentais sobre a fantasia, sejam estudados em diferentes culturas. A fim de se identificar quais as contribuições e riscos do fenômeno ao desenvolvimento, mais estudos com jovens e adultos, ou até mesmo longitudinais são desejáveis. Em especial, novas pesquisas com crianças em situação de risco socioeconômico colaborariam para uma melhor compreensão dos fatores protetivos sugeridos até então. Atualmente, as habilidades associadas ao fenômeno que precisam ser mais bem exploradas são a criatividade, a cognição social e a linguagem. $\mathrm{O}$ procedimento de entrevista sobre amigos imaginários, desenvolvido por Taylor e colegas é criterioso e poderia ser utilizado em pesquisas futuras, assim como o emprego de grupo de comparação e de medidas controle (e.g., linguagem e nível socioeconômico).

Finalmente, é importante destacar que a pesquisa nacional sobre o fenômeno pode ajudar a desmistificar essa forma de faz de conta, sobre a qual pouco ou nada se fala na mídia e na comunidade científica, bem como colaborar com a instrução de pais e educadores sobre o que a criação de amigos imaginários pode significar para as crianças. Considerando que os amigos imaginários são parte da rede social da criança (Gleason, 2002), e que tais redes variam de acordo com a cultura, Gleason et al. (2003) teorizam que a criação de amigos imaginários pode variar de acordo com aspectos étnicos e culturais. Pesquisas brasileiras sobre o fenômeno da criação de amigos imaginário também podem contribuir nessa direção, identificando tanto aspectos universais como aqueles que variam em função da cultura.

\section{REFERÊNCIAS}

Alves, A. C. S., Dias, M. G. B. B., \& Sobral, A. B. C. (2007). A relação entre a brincadeira de faz-de-conta e o desenvolvimento de habilidades na aquisição de uma teoria da mente. Psicologia em estudo, 12(2), 325-334. http:// dx.doi.org/10.1590/S1413-73722007000200013

* Bittencourt, C. M., \& Blanco, D. C. (1996). O amigo imaginário na percepção das mães. Psico, 27(2), 139-151.

* Bouldin, P. (2006). An investigation of the fantasy predisposition and fantasy style of children with imaginary companions. The Journal of Genetic Psychology, 167(1), 17-29. http://dx.doi.org/10.3200/GNTP.167.1.17-29

* Bouldin, P., Bavin, E. L., \& Pratt, C. (2002). An investigation of the verbal abilities of children with imaginary companions. First Language, 22, 249-264. http://dx.doi.org/10.1177/014272370202206602

* Bouldin, P., \& Pratt, C. (1999). Characteristics of preschool and school-age children with imaginary companions. The Journal of Genetic Psychology, 160(4), 397-410. doi: 10.1080/00221329909595553

* Bouldin, P., \& Pratt, C. (2002). A systematic assessment of the specific fears, anxiety level, and temperament of children with imaginary companions. Australian Journal of Psychology, 54(2), 79-85. http://dx.doi.org/10.1080/0004953021 0001706533 
*Brinthaupt, T. M., \& Dove, C. T. (2012). Differences in self-talk frequency as function of age, only-child, and imaginary childhood companion status. Journal of Research in Personality, 46, 326-333. http://dx.doi.org/10.1016/j. jrp.2012.03.003

Bukowski, W., Newcomb, A. \& Hartup, W. (1996). The company they keep: Friendship in childhood and adolescence. Cambridge: Cambridge University Press.

* Carlson, S. M, Tahiroglu, D., \& Taylor, M. (2008). Links between dissociation and role play in a nonclinical sample of preschool children. Journal of Trauma \& Dissociation, 9(2), 149-171. http://dx.doi.org/10.1080/15299730802045799

* Carlson, S. M., \& Taylor, M. (2005). Imaginary companions and impersonated characters: Sex differences in children's fantasy play. Merrill-Palmer Quarterly, 51,93-118. http://dx.doi.org/10.1353/mpq.2005.0003

Daudt, P. R., Souza, L. K., \& Sperb, T. M. (2012). Amizade na criança pequena: padrões de interação e diferenças de gênero. In L. K. Souza \& C. S. Hutz (Eds.), Amizade em contexto: Desenvolvimento e cultura. (pp. 81-100). São Paulo: Casa do Psicólogo.

* Davis, P. E., Meins, E., \& Fernyhough, C. (2011). Self-knowledge in childhood: Relations with children's imaginary companions and understanding of mind. British Journal of Developmental, 29(3), 680-686. http://dx.doi.org/10.1111/ j.2044-835X.2011.02038.x

* Davis, P. E., Meins, E., \& Fernyhough, C. (2013). Individual differences in children's private speech: The role of imaginary companions. Journal of Experimental Child Psychology, 116, 561-571. http://dx.doi.org/10.1016/j. jecp.2013.06.010

Dias, M. G. (1992). A brincadeira de faz-de-conta como capacidade para diferenciar entre o real e o imaginário. Psicologia: Teoria \& Pesquisa, 8(3), 363-371.

*Fernyhough, C., Bland, K., Meins, E., \& Coltheart, M. (2007). Imaginary companions and young children's responses to ambiguous auditory stimuli: Implications for atypical development. Journal of Child Psychology and Psychiatry, 48(11), 1094-1101. http://dx.doi.org/10.1111/j.1469-7610.2007.01789.x

* Gleason, T. R. (2002). Social provisions of real and imaginary relationships in early childhood. Developmental Psychology, 38(6), 979-992. http://dx.doi.org/10.1037/0012-1649.38.6.979

* Gleason, T. R. \& Hohmann, L. M. (2006). Concepts of real and imaginary friendships in early childhood. Social Development, 15(1), 128-144. http://dx.doi.org/10.1111/j.1467-9507.2006.00333.x

* Gleason, T. R., Jarudi, R. N., \& Cheek, J. M. (2003). Imagination, personality, and imaginary companions. Social Behavior and Personality, 31(7), 721-738. http://dx.doi.org/10.2224/sbp.2003.31.7.721

* Gleason, T. R., Sebanc, A., \& Hartup, W. (2000). Imaginary companions of preschool children. Developmental Psychology, 36, 419-428. doi: 10.1037/0012-1649.36.4.419

Harris, P. L. (2000). The work of the imagination. Oxford: Blackwell.

* Harter, S., \& Chao, C. (1992). The role of competence in children's creation of imaginary friends. Merrill-Palmer Quarterly, 38, 350-363.

*Hoff, E. V. (2005a). A friend living inside me - The forms and functions of imaginary companions. Imagination, Cognition and Personality, 24, 151-189. http://dx.doi.org/10.2190/4M9J-76M2-4Q4Q-8KYT

* Hoff, E. V. (2005b). Imaginary companions, creativity, and self-image in middle childhood. Creativity Research Journal, 17 (2-3), 167-180. http://dx.doi.org/10.1080/10400419.2005.9651477

Leslie, A. S. (1987). Pretense and representation: The origins of "theory of mind". Psychological Review, 94(4), 412-426. http://dx.doi.org/10.1037/0033-295X.94.4.412

Lillard, A. S. (2007). Pretend play in toddlers. In C. A. Brownell \& C. B. Kopp (Eds.), Socioemotional development in the toddler years: Transitions \& transformations (pp. 149-174). New York, NY: Guilford Press.

Lisboa, C. (2012). Quem tem um amigo nunca está sozinho? Ou antes só do que mal acompanhado? Relações de amizade: Fatores de risco e proteção. In L. K. Souza \& C. S. Hutz (Eds.), Amizade em contexto: Desenvolvimento e cultura (pp. 81-100). São Paulo: Casa do Psicólogo.

Macedo, L. (2003). Faz-de-conta na escola: A importância do brincar. Pátio Educação Infantil, 3, 10-13.

* Manosevitz, M., Prentice, N., \& Wilson, F. (1973). Individual and family correlates of imaginary companions in preschool children. Developmental Psychology, 8, 72-79. http://dx.doi.org/10.1080/01650250344000415

Oliveira, Z. M. R., Mello, A. M., Vitória, T., \& Rossetti-Ferreira, M. C. (1993). Creche: Crianças, faz-de-conta \& cia. Petrópolis, RJ: Vozes.

Piaget, J. \& Inhelder, B. (1968). A função semiótica ou simbólica. In A Psicologia da Criança. São Paulo: Difusão Européia do Livro. (Original publicado em 1945)

Piotto, D. \& Rubiano, M. R. B. (1999). Amizade entre crianças pequenas: Análise da interação de pares preferenciais na creche. Psico, 30, 109-129.

Preissler, M. A. (2006). Play and autism: Facilitating symbolic understanding. In D. G. Singer, R. M. Golinkoff \& K. HirshPasek (Eds.), Play = learning: How play motivates and enhances children's cognitive and socio-emotional growth (pp. 231-250). New York: Oxford University Press. http://dx.doi.org/10.1093/acprof:oso/9780195304381.003.0012

* Roby, A. C. \& Kidd, E. (2008). The referential communication skills of children with imaginary companions. Developmental Science, 11(4), 531-540. http://dx.doi.org/10.1111/j.1467-7687.2008.00699.x

* Seiffge-Krenke, I. (1997). Imaginary companions in adolescence: Sign of a deficient or positive development? Journal of Adolescence, 20, 137-154. http://dx.doi.org/10.1080/01650250344000415 
Silva, G. R. \& Garcia, A. (2008). Os primórdios da amizade na infância: A perspectiva materna. Paidéia, 18(41), 591604. http://dx.doi.org/10.1590/S0103-863X2008000300014

Smith, E. D. \& Lillard, A. S. (2012). Play on: Retrospective reports of the persistence of pretend play into middle childhood. Journal of Cognition and Development, 13(4), 524-549. http://dx.doi.org/10.1080/15248372.2011.608199

Sperb, T. M. \& Carraro, L. (2008). A relação entre o faz-de-conta e a teoria da mente: Controvérsias teóricas e empíricas. In T. M. Sperb \& M. R. Maluf (Eds.), Desenvolvimento sociocognitivo: Estudos brasileiros sobre "teoria da mente". (pp. 163-190). São Paulo, SP: Vetor.

* Svendsen, M. (1934). Children's imaginary companions. Archives of Neurology and Psychiatry, 32, 985-999. http:// dx.doi.org/10.1001/archneurpsyc.1934.02250110073006.

Tavares, L. C., \& Pinheiro, M. L. (1989). O amigo imaginário. Psico, 17(1), 150-163.

* Taylor, M. (1999). Imaginary companions and the children who create them. Melbourne: Oxford University Press.

* Taylor, M. \& Carlson, S. M. (1997). The relation between individual differences in fantasy and theory of mind. Child Development, 68(3), 436-455. http://dx.doi.org/10.2307/1131670

* Taylor, M. \& Carlson, S. M. (2002). Imaginary companions and elaborate fantasy in childhood. In R. W. Mitchell (Ed.), Pretending and imagination in animals and children (pp. 167-180). Cambridge: Cambridge University Press. http:// dx.doi.org/10.1017/CBO9780511542282.014

* Taylor, M., Carlson, S. M., Maring, B., Gerow, L., \& Charley, C. M. (2004). The characteristics and correlates of fantasy in school-age children: Imaginary companions, impersonation, and social understanding. Developmental Psychology, 40, 1173-1187. http://dx.doi.org/10.1037/0012-1649.40.6.1173

* Taylor, M., Cartwright, B. S., \& Carlson, S. M. (1993). A developmental investigation of children's imaginary companions. Developmental Psychology, 29, 276-285. http://dx.doi.org/10.1037/0012-1649.29.2.276

* Taylor, M. \& Mannering, A. M. (2006). Of Hobbes and Harvey: The imaginary companions of children and adults. In A. Goncu \& S. Gaskins (Eds.), Play and development: Evolutionary, sociocultural and functional perspectives (pp. 227-245). Mawah, NJ: Erlbaum Press.

* Taylor, M. \& Mottwiler, C. M. (2008). Imaginary companions: Pretending they are real but knowing they are not. American Journal of Play, 1, 47-54.

* Taylor, M., Shawber, A. B., \& Mannering, A. M. (2009). Children's imaginary companions: What is it like to have an invisible friend? In K. D. Markman, W. M. P. Klein \& J. A. Suhr (Eds.), Handbook of imagination and mental simulation (pp. 211-224). New York, NY: Psychology Press.

* Trionfi, G. \& Reese, E. (2009). A good story: Children with imaginary companions create richer narratives. Child Development, 80(4), 1301-1313. http://dx.doi.org/10.1111/j.1467-8624.2009.01333.x

Velludo, N. B. (2010). Brincando de faz de conta: Uma forma de aprender sobre a mente? (Monografia não publicada). Universidade Federal de São Carlos, São Carlos, SP.

Velludo, N. B. (2014). A criação de amigos imaginários: Um estudo com crianças brasileiras. (Dissertação de mestrado). Acesso via Biblioteca Digital de Teses e Dissertações da Universidade Federal de São Carlos.

Autores:

NATÁlia Benincasa Velludo - Universidade Federal de São Carlos.

DÉBORA DE HOLlandA SOUZA - Universidade Federal de São Carlos.

Endereço para correspondência:

Natália Benincasa Velludo

Universidade Federal de São Carlos

Programa de Pós-Graduação em Psicologia

Rodovia Washington Luís, Km 235

CEP 13565-905 São Carlos, SP, Brasil

E-mail: nataliabvelludo@hotmail.com

Recebido em: 28.02.13

Aceito em: 08.10.14 